\title{
Research on the Consumer Market of College Students in Hebei Province
}

\author{
Hang Zhang ${ }^{1,}$, Yanting Ren ${ }^{2, b}$ \\ ${ }^{1}$ School of economy and management, Shijiazhuang Tiedao University, Shijiazhuang 050043, \\ China; \\ ${ }^{2}$ School of economy and management, Shijiazhuang Tiedao University, Shijiazhuang 050043 , \\ China. \\ a012822552@qq.com, , '1185627787@qq.com, cyyyy@ccc.com
}

Keywords: Consumer market, college students, factors.

\begin{abstract}
As a group of special consumers, college students play an indispensable role in today's life and their consumption is arousing more and more concern of the society. This paper, based on a survey we made to research the condition of students' consumption, presents ways in which university students spend their money, and analyze problems and provides solutions. Therefore this paper can guide university students to more scientific and reasonable consumption.
\end{abstract}

\section{Introduction}

As we all know, there are a lot of college students in our country and the percentage is going to higher and higher. That is why more and more economists are paying attention to the consumer market. Some researches about the consumer market of college students focus on the distinctions of college students' consumption and the influence factors from society.

Many good researches have made to study the market and behavior of college students' consumption in which the ideas we can't agree more. For example, Yunying Bao's expounded the distinctions, misunderstanding and reasons about the behavior of college students' consumption and gave some suggestions to solve the problems in her study named analysis of college students consuming behavior under market economy. Lihong Wang and Yagang Du focus on guiding university students to more scientific and reasonable consumption when they Talk about the distinction and suggestions of college students' consumption. Research on the consumer market of college students in Nanning Province and marketing suggestions written by Xiaofei Jiang showed the situation and features of college students' consumption and he gave some marketing suggestions for enterprises basing on the problem.

There are few researches studying the consuming behavior of college students with a statistical tool when they analyze the relationship between the consuming behaviors and expenditure though some people used data. This paper examines the factors playing important parts in the way college students spend their money from the point of mentality rather than economy with SPSS statistical software. And accordingly, some useful suggestions will be given to solve the problems.Do not number your paper: All manuscripts must be in English, also the table and figure texts, otherwise we cannot publish your paper. Please keep a second copy of your manuscript in your office. When receiving the paper, we assume that the corresponding authors grant us the copyright to use the paper for the book or journal in question.

\section{Current situation}

We made a research with many kinds of questions to know about the situation of college students' consumption. There were about five hundred college students from kinds of universities in Hebei Province.

According to our survey, more than half students who were interviewed spend 500 to 1000 yuan a month, and only 3.96\% of the students spend more than 2000 yuan; about $78 \%$ of the students' 
expenditures account for $60 \%$ to 100 of the money they own, while $4.63 \%$ of the students spend more than they own, which indicates that most of college students' expenditure is appropriate. 95\% of the students get their living expenses mainly from their parents. But the source of the expense becomes more diversified because of the rise of grade.

For many students, they spend most of their money on food, clothes, communication fees and kinds of parties. Most of the students travel to some place. There are $48.68 \%$ of the students spending less than 1000 yuan and $24.67 \%$ of the students spend 1000 to 3000 yuan. $37.67 \%$ of the students have changed a phone, $27.09 \%$ of the students have changed two and $24.89 \%$ of the students have never changed their phones. There are several persons go to some slap-up places like Starbucks among the students interviewed.

When asked the reasons why they change their clothes and electronics, 55\% of the students said the old one was broken, $24 \%$ of the students said they need more, and only $13 \%$ of the students said they like new product or they just follow others. When talk about the direction of consumption, $55.07 \%$ of the students hope to keep balance between material and mentality, $16.3 \%$ of the students want to increase mentality consumption, $24.7 \%$ of the students haven't thought about it.

\section{Influence factors}

According to economic theory, consuming behavior is depended on many factors including price, income, consumers' preference and so on, as some people have proved it. We analyze the relationship between expense and mentality here. The objectives like the characteristics of commodities, the thoughts while shopping and the consumption level of classmates are listed. As shown in the following tables, we compare and analyze the collected data by the means of crosstabs.

Take the characteristics of the commodities the students pay attention for example, from the crosstabs, as for the "practical use", the percentages of the four kinds of expenditure are $10.8 \%$ 、 $64.4 \% 、 22.5 \%$ and $2.3 \%$ respectively; as for the "fashion", they are $0 \% 、 28.9 \% 、 60.5 \%$ and $10.5 \%$ respectively; as for the "brand", the percentages of the four kinds of expenditure are $2.9 \%$ 、34.3\%、 $51.4 \%$ and $11.4 \%$ respectively; as for the "price", the percentages of the four kinds of expenditure are $20.7 \%$-51.7\%、27.6\% and $0 \%$ respectively; as for the "others", the percentages of the four kinds of expenditure are $5.9 \% 、 41.2 \% 、 35.3 \%$ and $17.6 \%$ respectively. It is obvious that most of the students whose expenditures are not high are pay attention to the practical use of commodities rather than fashion and brand.

In the same way, we can see that college students' thought when they are shopping and the consumption level of their classmates also make a important difference in their expenditure.

In a word, college students' behavior of consumption is related to some factors about mentality. Taking all these factors into consideration, we can know that college students' consuming behavior is not independent. College students spend their money not only depend on their own decisions, but also affect from the behavior of others around them.

The following tables show the results of the test:

Table 1 Expenditure characteristics of commodities crosstabulation

\begin{tabular}{ccccc}
\hline Numble & Pratical use & Brand & Price & Others \\
\hline$<500$ & $10.8 \%$ & $.0 \%$ & $2.9 \%$ & $20 . \%$ \\
& 33 & 0 & 1 & 12 \\
$500-1000$ & $64.4 \%$ & $28.9 \%$ & $34.3 \%$ & $51 . \%$ \\
& 197 & 11 & 12 & 30 \\
$1000-2000$ & $22.5 \%$ & $60.5 \%$ & $51.4 \%$ & $27 . \%$ \\
& 69 & 23 & 18 & 16 \\
$>2000$ & $2.3 \%$ & $10.5 \%$ & $11.4 \%$ & $.0 \%$ \\
& 7 & 4 & 4 & 0 \\
Total & $100 \%$ & $100 \%$ & $100 \%$ & $100 \%$ \\
& 306 & 38 & 35 & 58 \\
\hline
\end{tabular}


Table 2 Expenditure * thought while shopping crosstabulation

\begin{tabular}{ccccc}
\hline Expenditure & $\begin{array}{c}\text { Buy it even } \\
\text { expensive }\end{array}$ & $\begin{array}{c}\text { Not too } \\
\text { expensive }\end{array}$ & $\begin{array}{c}\text { Shop } \\
\text { around }\end{array}$ & Others \\
\hline$<500$ & $3.8 \%$ & $8.3 \%$ & $15.0 \%$ & $12.5 \%$ \\
$500-1000$ & 2 & 18 & 25 & 2 \\
& $39.6 \%$ & $59.2 \%$ & $58.7 \%$ & $56.2 \%$ \\
$1000-2000$ & 21 & 129 & 98 & 9 \\
& $50.9 \%$ & $29.4 \%$ & $22.2 \%$ & $25.0 \%$ \\
$>2000$ & 27 & 64 & 37 & 4 \\
& $5.7 \%$ & $3.2 \%$ & $4.2 \%$ & $6.20 \%$ \\
Total & 3 & 7 & 7 & 1 \\
& $100 \%$ & $100 \%$ & $100 \%$ & $100 \%$ \\
& 53 & 218 & 167 & 16 \\
\hline
\end{tabular}

Table 3 expenditure * classmates' consuming level crosstabulation

\begin{tabular}{cccccc}
\hline Numble & $\begin{array}{c}\text { very } \\
\text { high }\end{array}$ & high & appropriate & low & $\begin{array}{c}\text { very } \\
\text { low }\end{array}$ \\
\hline$<500$ & $16.7 \%$ & $10.7 \%$ & $10.8 \%$ & $4.8 \%$ & $.0 \%$ \\
& 3 & 15 & 27 & 2 & 0 \\
$500-1000$ & $66.7 \%$ & $57.1 \%$ & $60.8 \%$ & $28.6 \%$ & $25.0 \%$ \\
& 12 & 80 & 152 & 12 & 1 \\
$1000-2000$ & $16.7 \%$ & $30.0 \%$ & $25.2 \%$ & $54.8 \%$ & $25.0 \%$ \\
& 3 & 42 & 63 & 23 & 1 \\
$>2000$ & $0 \%$ & $2.1 \%$ & $3.2 \%$ & $11.9 \%$ & $50.0 \%$ \\
& 0 & 3 & 8 & 5 & 2 \\
Total & $100 \%$ & $100 \%$ & $100 \%$ & $100 \%$ & $100 \%$ \\
& 18 & 140 & 250 & 42 & 4 \\
\hline
\end{tabular}

\section{Summary}

From the result of the research, a number of students' expenditures are appropriate, which explains that most of them could keep their expenditures within the limits of income, make a appropriate decision on consumption without following others blindly. But we also can see that there are some college students who pursue fashion and brand and compare with others blindly. These students spend much more money for entertainment which is different from others even our traditional culture about frugalness.

To avoid the bad habit making a difference in the consumer atmosphere and promote a better consuming condition for college students, some effective suggestions are given here.

First, the guidance about consuming should be strengthened to promote the consumer atmosphere. A small number of college students whose expenditure are much more than others should be remind to be frugal.

Second, college students should be educated more about consuming to improve the ability of scientific financing. Planned consumption should be known and it is good for college students to have mental consumption and developmental consumption to maximize the consuming benefit.

Last but not least, it is necessary for government to encourage college students to start their own business or have a part-time job to support themselves. Effective measures are necessary like financial support.

To sum up, more attention should be taken to college students, a more and more important group, especially the consumer market of college students including their consuming behavior, distinctions and other fields. On the one hand, it will help college students develop better consuming habits and on the other hand, our country's economy will benefit from a wonderful consuming condition that many people especially college students, the main force in the future, have a good sense of economy and develop themselves by spend the money they have. 


\section{Acknowledgement}

This paper is the achievement of the nationwide project for college students' innovation and entrepreneurship in 2015 of which number is 201510107057.

\section{References}

[1]. Yunying bao, et al. Analysis of college students consuming behavior under market economy. Coastal Enterprises And Science \& Technology. Vol.10 (2009).

[2]. Lihong Wang, Yagang Du, et al. Talk about the distinction and suggestions of college students' consumption. Science Information. Vol.7 (2007)

[3]. Xiaofei Jiang, et al. Research on the consumer market of college students in Nanning Province and marketing suggestions. Nationwide Chinese Central Magazine. Vol.20(2006) 